\title{
Editorial: Introducing the Journal of Operational Meteorology
}

We are pleased to announce that the National Weather Association (NWA) leadership has approved the Publications Committee proposal to merge the NWA Digest and Electronic Journal of Operational Meteorology (EJOM) into an all-electronic journal called the Journal of Operational Meteorology (JOM, nwas.org/jom). This decision was vetted through the Publications Committee, the Digest and EJOM Editors, the NWA Council, external input from libraries, and a survey of the paper subscribers to the Digest. Although not everyone was in favor of this move, a large majority of members believe it is a wise decision in terms of cost effectiveness, efficiency, and environmental stewardship.

The JOM's official inauguration is January 1st, 2013, but there will be a period of transition from the legacy Digest and EJOM to the new JOM.

There are four categories of submission for the JOM:

- Articles

- Short Contributions

- Images of Note

- Commentaries

The Articles and Short Contributions are of similar length as Digest and EJOM articles, respectively. The Images of Note are the same as were published in the EJOM, and the Commentaries are a new addition that allows authors to discuss recently published JOM papers.

The Journal Charter specifies topics that are appropriate for the JOM:

Published by the National Weather Association, the Journal of Operational Meteorology covers topics relevant to all aspects of operational meteorology on a range of time and space scales. Suitable topics include new or improved forecasting and warning techniques, verification studies, applications of observations and models to improve forecasts and warnings, and case studies of major weather events. Climatological studies, interdisciplinary studies, and studies documenting education and training practices also will be considered if relevant to operational meteorology. In addition, the Editors welcome submissions that present strategies for the creation and dissemination of forecasts and warnings that maximize the protection of life and property. JOM is a peer-reviewed, all-electronic journal with an international scope, providing authors with the benefits of economical publication costs and rapid publication following acceptance.

The cost of publishing Articles is greatly reduced compared to the Digest. Slight upward cost adjustments have been made with respect to the EJOM, but these are still reasonable prices compared to other all-electronic publications. The new JOM will be published on a per article basis, which will facilitate more rapid dissemination of peer-reviewed research. In addition, it is hoped that combining the two journals will help qualify the JOM to be ranked by Thomson-Reuters (http://thomsonreuters.com/products services/science/academic/). The value of the ranking is determined by the number of times JOM articles are referenced in other publications, which is looked upon favorably by several academic and research institutions. Achieving ranked-journal status also may lead to an increased pool of JOM authors and readers, thus broadening the reach of the NWA. 
There will continue to be modifications to the JOM infrastructure as 2013 progresses, but these modifications will be transparent to readers. Members and nonmembers alike are encouraged to learn about the journal submission process, and to submit for publication any studies that fall under the JOM charter. Please consider promoting the JOM to colleagues who may be interested in submitting and reading articles on operational meteorology, and also consider signing up for free notifications of new articles (nwas.org/jom).

The NWA is largely a volunteer organization, and thus this transition would not have been possible without the advice and support from many individuals. Initial support to consider the transition to the JOM was given by Jeff Craven and Alan Gerard, and continued support through the NWA Council was provided by John Gordon. The development of the JOM was guided by several current and past NWA Publications Committee members (Justin Arnott, Michael Brown, Jeff Craven, Grady Dixon, Rich Grumm, Pat Market, Jeffrey Medlin, and Pablo Santos) as well as Digest and EJOM editors (Paul Croft, Tony Lupo, and Mike Brennan). Support for website development was provided by Steve Listemaa and Tim Oram. Moreover, Roger Edwards and David Schultz answered several questions throughout the development phase of the JOM based on their experience with the Electronic Journal of Severe Storms Meteorology (ejssm.org). Questions on library acquisition of electronic journals were answered by Patricia Anderson (South Dakota School of Mines \& Technology Library), Steve Quillen (NOAA Central Library), and Joan Segal (NOAA Boulder Labs Library). Finally, the NWA membership has been especially supportive throughout this transitional period. The critical feedback provided through surveys and informal discussions helped the NWA leadership make the decision to launch the JOM.

Matthew Bunkers

Chair, NWA Publications Committee

pubchair@nwas.org

Steven Weiss

Chief Editor, JOM

jom_editor@nwas.org

Michael Coniglio, Adam Clark, Martin Baxter, and Jon Zeitler

Editors, JOM

Daniel Lindsey

Member, NWA Publications Committee

Stephen Harned

Executive Direction, NWA

exdir@nwas.org

18 December 2012 